\title{
ANALYSIS OF EXPLOSION STRESS FIELD OF AIR RADIAL DECOUPLING CHARGE
}

\author{
Deqiang $\mathrm{YANG}^{1 *}$, Zhen $\mathrm{LEI}^{2}$, \\ Huaming $\mathrm{AN}^{3}$ \\ ${ }^{1}$ Civil and Resource Engineering School, University of Science and Technology Beijing, Beijing, \\ 100083, China \\ ${ }^{2}$ Guizhou Institute of Technology, Guiyang, 550003, China \\ ${ }^{3}$ Kunming University of Science and Technology, Kunming, 650093, China
}

\begin{abstract}
In order to study the effect of air radial decoupling charge on blasting excavation effect of slope, the effect of radial decoupling coefficient on explosive stress field in rock mass is analyzed theoretically. ANSYS/LS-DYNA software is used to establish a numerical model for stress monitoring of monitoring points. At the same time, the concrete model is poured, the explosion stress field around the blast hole is measured by means of the high-speed multi-channel dynamic stress testing system, and the monitoring results of the two methods are compared with the theoretical analysis results. The results show that with the increase of the radial decoupling coefficient of blasting, the peak value of explosive stress at the same side point decreases obviously, and with the increase of the distance, the stress attenuation becomes slower. Applying the test results to the blasting of slope, it is found that the blasting effect is the best when the aperture decoupling coefficient is 2.75 and the hole spacing is $1.0 \mathrm{~m}$, and the larger the hole spacing is, the less obvious the blasting crack is, which has certain guiding significance for improving the blasting effect.
\end{abstract}

Keywords: air radial decoupling charge, explosion stress field, concrete model, numerical simulation

\section{INTRODUCTION}

The explosive stress field in the rock around the blasthole is closely related to the charging structure. Different charging structures make the effective utilization rate of

\footnotetext{
* Corresponding author: zydqyang@163.com (Y. Deqiang)
} 
the explosive energy of the explosive different, and the blasting effect obtained is different.

$\mathrm{Xu}$ et al. (2011) studied how to realize the decoupling of charge. Qu et al. (2014) analyzed the influence of different charge structure and initiation mode on blasting effect by using LS-DYNA software. Yang et al. (2012) studied systematically the pressure distribution in the hole under different air-spaced charge conditions by numerical calculation method. The results show that the pressure at each point in the hole of air-spaced charge is not equal, and the initial impact pressure on the hole wall in the middle of charge section is the highest, which is significantly higher than that in the air column section. Ling (2004) used the manganese copper piezoresistive sensor and pulse constant current source test system to test the initial impact pressure of cement mortar and plexiglass medium under the condition of coupling and decoupling charge, and obtained the initial impact pressure value of hole wall at each point, which provides a reference for the direct measurement of this value. Yang et al. (1996) exploded the cement mortar concrete with air decoupling charge to optimize the decoupling coefficient. Wan et al. (2003) made a theoretical analysis on the calculation of initial impact pressures of five kinds of decoupled charges.

Taking the controlled blasting construction of a slope as an example, the blasting effect of radial coupling coefficient and hole spacing blasting is analyzed and compared by theoretical derivation, model test, numerical simulation and field test methods. By adjusting the decoupling coefficient and hole spacing, the blasting excavation effect of a slope can be remarkable, which can provide a reference for the similar slope excavation engineering.

\section{THEORETICAL BASIS}

\subsection{INITIAL IMPACT PRESSURE ON HOLE WALL OF AIR RADIAL DECOUPLING CHARGE}

There is air between the charge and the hole wall. After explosion, the explosive first produces air shock wave in the air gap, and then the air shock wave collides with the hole wall to produce hole wall pressure (Ni et al. 1996; Ling 2004).

Based on the assumptions that the detonation air shock wave enters the hole wall directly and the hole wall is rigid wall (Xu et al. 2001):

$$
P \geq P_{K}, \quad P_{b}=\frac{\beta \rho_{e} D^{2}}{2(k+1)} \times K_{d}^{-2 k},
$$




$$
\begin{gathered}
P<P_{K}, \quad P_{b}=\beta P_{K}\left(\frac{P_{0}}{P_{K}}\right)^{\gamma / k} \times K_{d}^{-2 \gamma}, \\
P_{0}=\frac{\rho_{e} D^{2}}{2(k+1)},
\end{gathered}
$$

where: $P$ is the gas expansion pressure, $\mathrm{MPa} ; P_{K}$ is the critical pressure of the stage gas, $P_{K}=200 \mathrm{MPa} ; P_{b}$ is the initial impact pressure of the hole wall, $\mathrm{MPa} ; P_{0}$ is the mean detonation pressure, $\mathrm{MPa} ; \beta$ is that pressure increase multiple of the hole wall, it is generally taken $\beta=8 \sim 11 ; \rho_{e}$ is the density of explosives, $\mathrm{g} \cdot \mathrm{cm}^{-1} ; D$ is the detonation velocity, $\mathrm{m} \cdot \mathrm{s}^{-1} ; K_{d}$ is the radial decoupling coefficient, $K_{d}=d_{b} / d_{c}$, where is the diameter of the blasthole, $\mathrm{cm} ; d_{c}$ is the diameter of the charge in the blasthole, $\mathrm{cm}$; $k$ is isentropic expansion index, generally taken $k=3 ; \gamma$ is the adiabatic expansion index, generally taken $\gamma=1.3$.

Since the gas expansion pressure at the moment of explosion is generally greater than the gas critical pressure, the formula (1) is used to calculate the initial pressure of the hole wall of the radial air decoupled charge. In order to compare with the model test and numerical simulation results, the same explosive parameters and rock medium as the model test are used in the calculation. Because the borehole diameter of model test is smaller than the critical diameter of emulsion explosive, the PETN is used.The main performance indicators of emulsion explosives and PETN are shown Table 1, and the calculated initial wall pressure of the radial air decoupled charge is shown in Table 2.

Table 1. The main performance indicators of emulsion explosives and PETN (Wang 2010)

\begin{tabular}{|l|c|c|}
\hline \multirow{2}{*}{\multicolumn{1}{|c|}{ Items }} & \multicolumn{2}{c|}{ Main performance indicators } \\
\cline { 2 - 3 } & Emulsion explosives & PETN \\
\hline Density, $\mathrm{g} \cdot \mathrm{cm}^{-3}$ & 1.2 & 1.1 \\
\hline Detonation velocity, $\mathrm{m} \cdot \mathrm{s}^{-1}$ & 4200 & 6721 \\
\hline Shattering effect, $\mathrm{mm}$ & 14 & 16 \\
\hline Strength power, $\mathrm{ml}$ & 260 & 500 \\
\hline Critical diameter $/ \mathrm{mm}$ & 20 & 2.1 \\
\hline
\end{tabular}

Table 2. Calculated results of pressure of the hole wall for air radial decouple charge

\begin{tabular}{|l|c|c|c|}
\hline Radial decoupling coefficient, $K_{d}$ & 1.50 & 2.25 & 2.75 \\
\hline Hole wall pressure, $\mathrm{MPa}$ & 4073.3 & 602.6 & 141.8 \\
\hline
\end{tabular}




\subsection{EXPLOSION STRESS FIELD OF AIR RADIAL DECOUPLED CHARGE}

The attenuation law of explosive stress wave of cylindrical charge is (Wang 1980; Niu 1990):

$$
\sigma_{r}=P_{b} \bar{r}^{-\alpha},
$$

where: $\sigma_{r}$ is the radial stress peak, MPa; $P_{b}$ is the initial impact pressure of the hole wall, MPa; $\bar{r}$ is the proportional distance, $\bar{r}=\frac{r}{r_{b}} ; r$ is the distance from the center of the blasthole, $r_{b}$ is the radius of the blasthole; $\alpha$ is the blast wave attenuation index, take 3 for blast wave, calculate stress wave as $\alpha=2-\frac{\mu}{1-\mu}$, and get stress wave attenuation index $\alpha=1.7$ for test model material $\mu=0.23$.

It is easy to get the explosive stress field when the initial impact pressure of the hole wall is substituted for the attenuation formula of the stress wave. The calculation results are shown in Table 3.

Table 3. Calculated results of stress field for air radial decouple charge

\begin{tabular}{|c|c|c|c|c|c|c|c|c|c|c|c|c|}
\hline$K_{d}$ & \multicolumn{4}{|c|}{1.50} & \multicolumn{4}{c|}{2.25} & \multicolumn{4}{c|}{2.75} \\
\hline $\bar{r}, \mathrm{~cm}$ & 5 & 10 & 15 & 20 & 5 & 10 & 15 & 20 & 5 & 10 & 15 & 20 \\
\hline$\sigma_{r}, \mathrm{MPa}$ & 244.3 & 81.5 & 40.7 & 25.0 & 39.1 & 12.1 & 6.0 & 3.7 & 9.2 & 2.8 & 1.4 & 0.9 \\
\hline
\end{tabular}

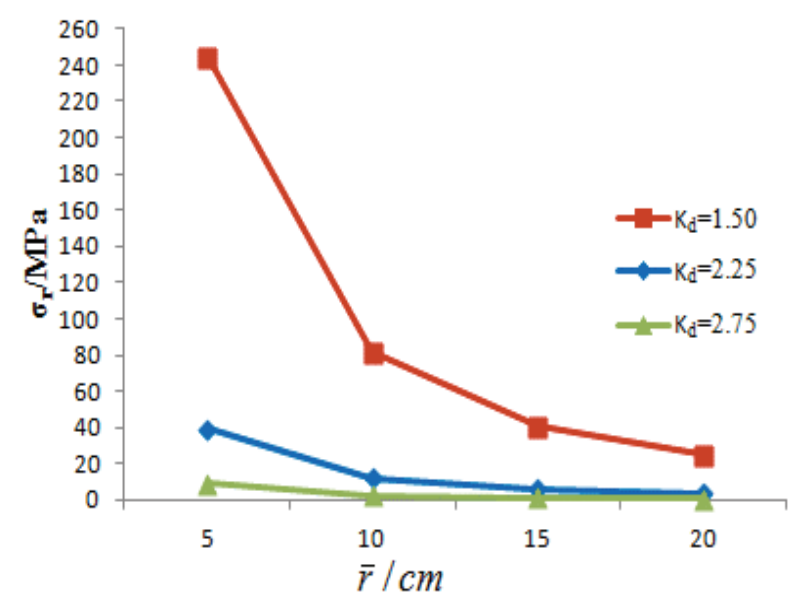

Fig. 1. Contrast curves of explosive stress field of charge with different air radial coupling coefficients 
In order to compare the attenuation law of rock stress field under different air radial coupling coefficients, the data in Table 3 are processed by Excel, and the contrast curves of explosive stress field of charge with different air radial coupling coefficients shown in Fig. 1 are obtained. As can be seen from Fig. 1, with the increase of the proportional distance, the peak pressure of the stress wave attenuates rapidly, while the greater the radial decoupling coefficient, the slower the peak pressure of the stress wave attenuates, which is conducive to maintaining the integrity and stability of the surrounding rocks.

\section{MODEL TEST OF AIR RADIAL DECOUPLING CHARGE BLASTING}

\subsection{PRINCIPLE AND SYSTEM OF STRESS MEASUREMENT}

The test is based on the principle of resistance strain. When the specimen is subjected to dynamic stress, the strain gauge pasted on the measuring point will produce corresponding strain along with the deformation of the specimen, which will cause the change of resistance. The strain of the specimen can be inversely calculated by converting the change of resistance into the change of voltage or current and recording the change of voltage or current with a display instrument. The calculation method is as follows (Han 2013):

$$
\varepsilon=\frac{4 U}{k U_{0} A},
$$

where: $\varepsilon$ is the strain of the specimen; $U$ is the output voltage, $\mathrm{V} ; k$ is the sensitivity coefficient of the instrument, $k=2.00 ; U_{0}$ is instrument bridge pressure, $\mathrm{V}, U_{0}=2 \mathrm{~V}$; $A$ is the instrumentation gain, set to 100 .

Combined with Hooker's law: $P=\varepsilon E$, the stress at each point can be obtained, which $P$ is the stress value, MPa.

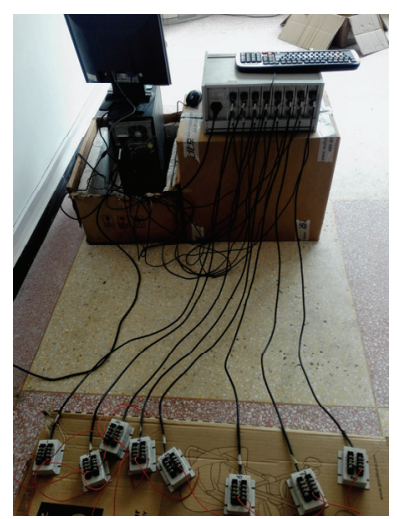

Fig. 2. Test system for stress monitoring 
As the data acquisition equipment, the strain gauge is pasted on the prefabricated strain brick and embedded in the concrete model as the sensor to receive the explosion signal. The instrument is shown in Fig. 2.

\subsection{PREPARATION OF CONCRETE MODEL}

According to the "Code for Construction and Acceptance of Concrete Structures" (GB50204-2015) and "Code for Design of Mixture Ratio of Concrete" (JGJ55-2011) and other relevant national standards and blasting similarity criteria, the strength of the model concrete is C30. The model material is poured by P.O42.5 ordinary Portland cement, sand, macadam and water according to the mass ratio of $1: 1.556: 3.158: 0.52$. The size of the concrete model is $50 \times 50 \times 30 \mathrm{~cm}$. There were 3 holes in the center of the test block with a depth of $15 \mathrm{~cm}$ and the diameters of $1.2,1.8$ and $2.2 \mathrm{~cm}$, respectively, which were cured for 28 days. The model design and specimens are shown in Figs. 3 and 4.

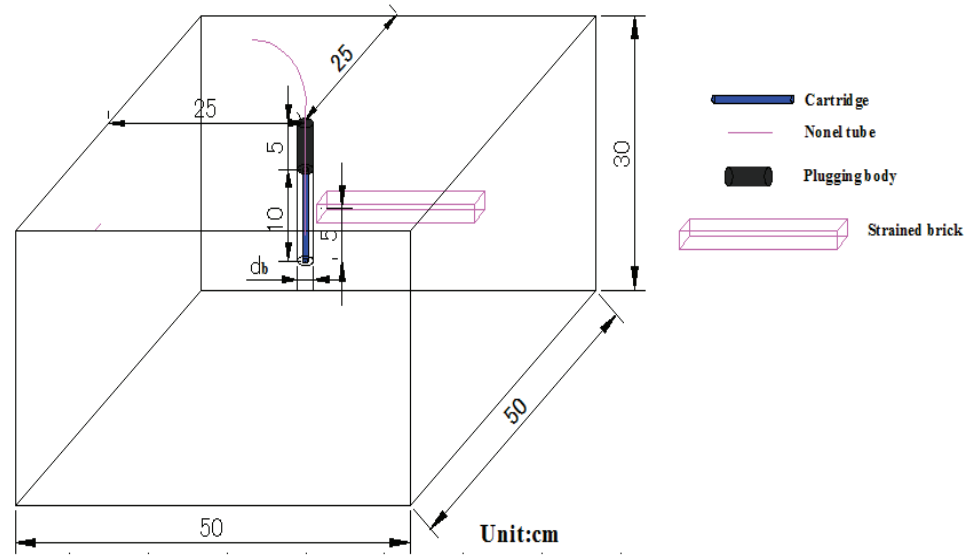

Fig. 3. Layout of model and measuring point

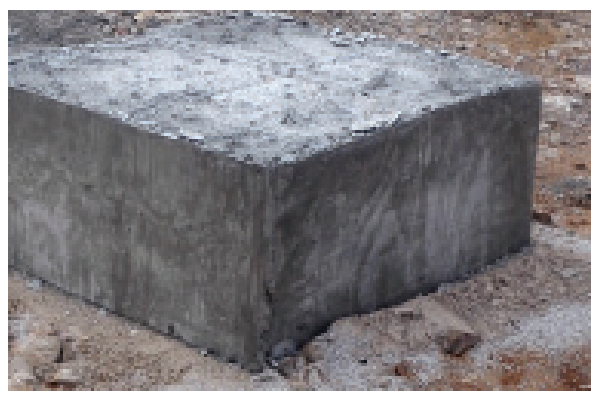

Fig. 4. Concrete model 
Strain bricks are made into cuboids with dimensions of length $\times$ width $\times$ height $=20 \times 5 \times 2 \mathrm{~cm}$. In order to ensure that the instantaneous signal of explosion is transmitted to the strained brick without reflection, the wave impedance of the strained brick and the experimental model should be strictly consistent (Ma et al. 2001 and Zong 2004). Therefore, the ratio of cement: sand: water is 1: 1: 0.5 , three of them are involved, and the curing time is 28 day. In order to measure the explosion stress effectively, the strain bricks are arranged $5 \mathrm{~cm}$ from the bottom of the blast hole and about $3 \mathrm{~cm}$ from the wall of the blast hole. Two BX120-4AA strain gauges with the resistance of $120 \Omega$ and sensitivity coefficient of $2.08 \pm 1 \%$ were attached to each strain brick vertically in radial and tangential directions. Four measuring points were arranged. The first measuring point was $2 \mathrm{~cm}$ away from the boundary of the strain brick, and the spacing between the four measuring points was $5 \mathrm{~cm}$, as shown in Fig. 5. When the strain gauge is pasted, the surface of the specimen is polished in the direction of $45^{\circ}$ with respect to the axial direction of the strain brick, so as to ensure that the surface of the specimen is smooth and free of embedded gravel. Then the specimen is pasted with 502 Glue. When the glue is bonded, the strain gauge is pasted in the correct position quickly, and excess glue is extruded to ensure good contact between the strain gauge and the strain brick.

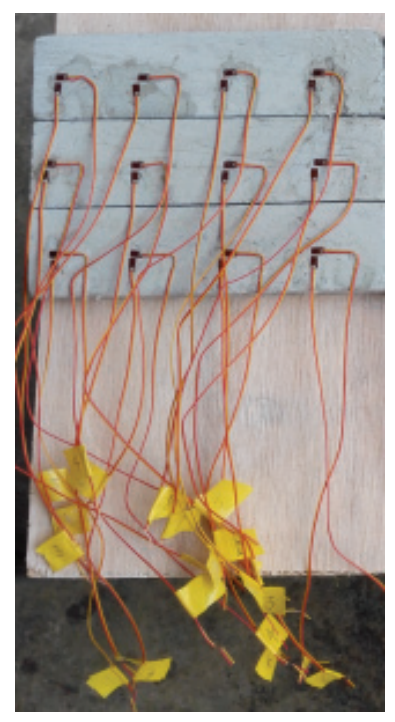

Fig. 5. Strain brick model

According to the same proportion and manufacturing process, three specimens were made for the study of physical and mechanical properties. The specimens were cylindrical in appearance, with a bottom diameter of $5 \mathrm{~cm}$ and a height of $10 \mathrm{~cm}$. After curing for 28 days, the relevant physical and mechanical properties were 
tested and the main mechanical parameters of the concrete model were obtained as shown in Table 4.

Table 4. Mechanical parameters of concrete mode

\begin{tabular}{|c|c|c|c|c|c|}
\hline $\begin{array}{c}\text { Test block } \\
\text { number }\end{array}$ & $\begin{array}{c}\text { Density, } \\
\mathrm{kg} \cdot \mathrm{m}^{-3}\end{array}$ & $\begin{array}{c}\text { Longitudinal } \\
\text { wave velocity, } \\
\mathrm{m} \cdot \mathrm{s}^{-1}\end{array}$ & $\begin{array}{c}\text { Elastic } \\
\text { modulus, } \\
\mathrm{GPa}\end{array}$ & $\begin{array}{c}\text { Compressive } \\
\text { strength, } \\
\mathrm{MPa}\end{array}$ & $\begin{array}{c}\text { Poisson } \\
\text { ratio }\end{array}$ \\
\hline 1 & 2247.12 & 3115 & 26.44 & 20.32 & 0.22 \\
\hline 2 & 2153.24 & 3067 & 25.85 & 30.08 & 0.23 \\
\hline 3 & 2177.00 & 3139 & 24.50 & 20.16 & 0.24 \\
\hline Average value & 2192.45 & 3100 & 25.50 & 23.52 & 0.23 \\
\hline
\end{tabular}

\subsection{EXPERIMENTAL METHODS}

Because of the small size of the model, the change of explosive charge has a great influence on the blasting effect, so it is difficult to design the gradient of explosive charge for effect comparison. Therefore, the control variables in this experiment make the charge diameter, charge amount, hole depth, hole blockage are the same in each group. The radial decoupling coefficient $K_{d}$ of air is changed by changing the hole diameter. After special treatment, the diameter of charge is $0.8 \mathrm{~cm}$, so the decoupling coefficients $K_{d}$ are 1.50,2.25 and 2.75 respectively when the diameter of the blast hole is $1.2 \mathrm{~cm}, 1.8 \mathrm{~cm}$ and $2.2 \mathrm{~cm}$. Under the condition of three decoupling coefficients, other influencing factors remain the same, the strain data of blasting process is collected, and the attenuation law of peak pressure of air radial decoupling charge with increasing proportional distance is analyzed.

\subsection{EXPERIMENTAL RESULTS}

Each model is loaded with $1 \mathrm{~g}$ PETN, detonated with a detonator, and the blast hole filling material is mixed with fine sand and 502 Glue. Test models filled with air

Table 5. Blasting experiments results of stress field for air radial decouple charge

\begin{tabular}{|c|c|c|c|c|}
\hline $\begin{array}{c}\text { Decoupling } \\
\text { coefficient, } K_{d}\end{array}$ & $\begin{array}{c}\bar{r}, \\
\mathrm{~cm}\end{array}$ & $\begin{array}{c}\text { Peak voltage, } \\
\mathrm{V}\end{array}$ & $\begin{array}{c}\text { Peak strain, } \\
\mu \varepsilon\end{array}$ & $\begin{array}{c}\text { Peak pressure, } \\
\mathrm{MPa}\end{array}$ \\
\hline \multirow{2}{*}{$\mathbf{1}$} & $\mathbf{2}$ & $\mathbf{3}$ & $\mathbf{4}$ & $\mathbf{5}$ \\
\hline \multirow{3}{*}{1.50} & 5 & 0.928 & 9280 & 236.64 \\
\cline { 2 - 5 } & 10 & 0.296 & 2960 & 75.48 \\
\cline { 2 - 5 } & 15 & 0.151 & 1510 & 38.51 \\
\cline { 2 - 5 } & 20 & 0.091 & 910 & 23.21 \\
\hline
\end{tabular}




\begin{tabular}{|c|c|c|c|c|}
\hline $\mathbf{1}$ & $\mathbf{2}$ & $\mathbf{3}$ & $\mathbf{4}$ & $\mathbf{5}$ \\
\hline \multirow{4}{*}{2.25} & 5 & 0.141 & 1410 & 35.95 \\
\cline { 2 - 5 } & 10 & 0.042 & 420 & 10.71 \\
\cline { 2 - 5 } & 15 & 0.02 & 200 & 5.11 \\
\cline { 2 - 5 } & 20 & 0.013 & 130 & 3.31 \\
\hline \multirow{5}{*}{2.75} & 5 & 0.033 & 330 & 8.42 \\
\cline { 2 - 5 } & 10 & 0.009 & 90 & 2.30 \\
\cline { 2 - 5 } & 15 & 0.005 & 50 & 1.28 \\
\cline { 2 - 5 } & 20 & 0.003 & 30 & 0.76 \\
\hline
\end{tabular}

medium and water medium and with decoupling coefficients of 1.50, 2.25 and 2.75 were blasted, respectively, and the data of explosion stress distribution of air radial decoupling charge were obtained, as shown in Table 5, which are typical waveforms of the test. Due to the damage of some channels of the ultra-dynamic strain gauge, the radial stress values of only four measuring points were measured.

\subsection{ANALYSIS AND DISCUSSION OF EXPERIMENTAL RESULTS}

Based on the test and calculation results in Table 5, the attenuation of the radial pressure peak around the blast hole with proportional distance for different air radial decoupling coefficients of charge is plotted, as shown in Fig. 6. Through regression calculation, the attenuation law of pressure peak value with radial propagation dis-

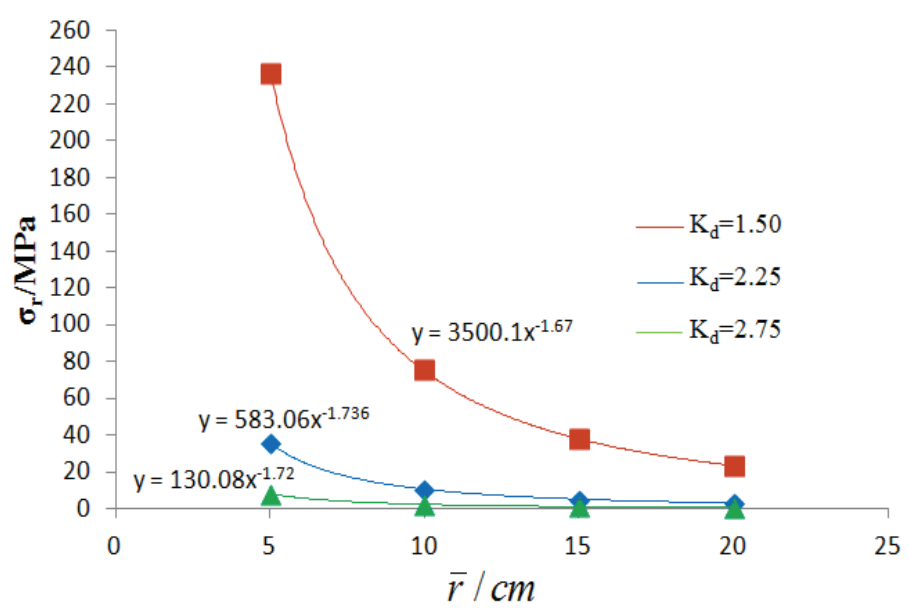

Fig. 6. Attenuation curve of explosion stress peak value with proportional distance of charge with different air radial decoupling coefficien 
tance around the blast hole during air-decoupled charge blasting can be obtained as follows:

$$
\begin{aligned}
& K_{d}=1.50, \quad \sigma_{r}=3500.1 \bar{r}^{-1.67}, \\
& K_{d}=2.25, \quad \sigma_{r}=583.06 \bar{r}^{-1.73}, \\
& K_{d}=2.75, \quad \sigma_{r}=130.08 \bar{r}^{-1.72} .
\end{aligned}
$$

From (6) to (8), it can be seen that the attenuation exponent of different radial decoupling coefficients has little difference with the calculated value, which further verifies the correctness of the theoretical calculation.

As can be seen from Fig. 6, with the increase of the radial decoupling coefficient, the peak pressure at the same side point obviously decreases, and with the increase of the distance, the slower the stress attenuation, the more conducive to maintaining the integrity and stability of the surrounding rocks.

\section{NUMERICAL SIMULATION VERIFICATION \\ 4.1. NUMERICAL MODELS AND PARAMETER SETTINGS}

Using ANSYS/LS-DYNA large dynamic finite element analysis software, a numerical model with one blasthole is established. Its geometric size, blasthole specification and blasthole arrangement are consistent with the subsequent concrete test model, as shown in Fig. 7. Three structural models of air radial decoupling charge with decoupling coefficients $K_{d}=1.50,2.25$ and 2.75 are established, respectively. The charge parameters corresponding to all models are shown in Table 6. In order to observe the initial impact pressure of the hole wall, the element $5 \mathrm{~cm}$ from the bottom of the hole and about $5 \mathrm{~cm}$ from the center of the hole was selected as the stress monitoring point, and the spacing between the four measuring points was $5 \mathrm{~cm}$.

In order to ensure the accuracy of numerical simulation results, rock material, explosive material, air spacer material and blast mud material are described by *MAT-PLASTIC-KINEMATIC, *MAT-HIGH-EXPLOSIVEBURN, *MAT-NULL and *MAT-SOIL-AND-FOAM models respectively. The state equations of explosive and air are described by * EOS-JWL and * EOS-POLYNO-MAIAL respectively. See Tables 7-10 for the values of parameters corresponding to each material model and its equation of state. The boundary conditions are set to: The top surface of the model is set as a free surface, and the remaining planes are set as non-reflecting boundaries. In the process of calculation, explosive material and air spacer material adopt ALE algorithm, rock material adopt Lagrange algorithm. 

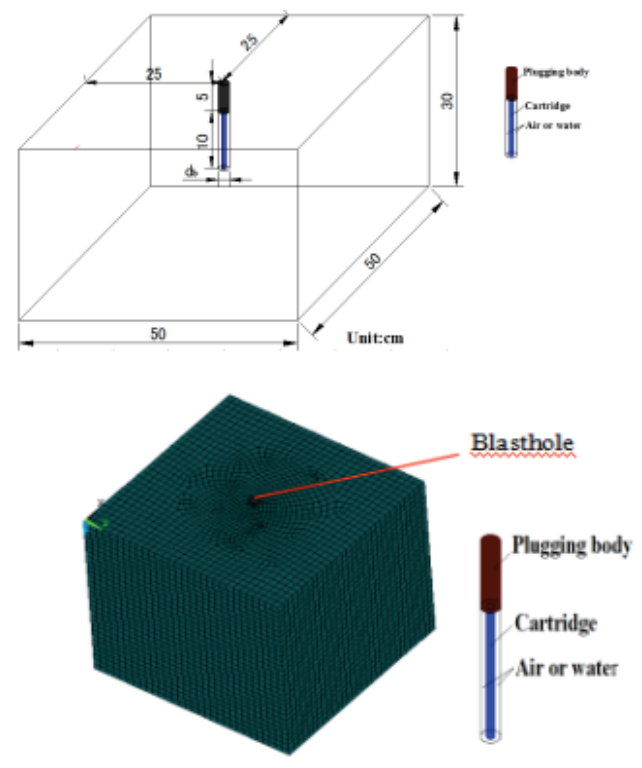

Fig. 7. Diagram of numerical simulation model

Table 6. Parameter setting of different charge condition

\begin{tabular}{|c|c|c|c|}
\hline$K_{d}$ & $\begin{array}{c}\text { Blasthole length, } \\
\mathrm{cm}\end{array}$ & $\begin{array}{c}\text { Blocking length, } \\
\mathrm{cm}\end{array}$ & $\begin{array}{c}\text { Charge length, } \\
\mathrm{cm}\end{array}$ \\
\hline 1.50 & 15 & 5 & 10 \\
\hline 2.25 & 15 & 5 & 10 \\
\hline 2.75 & 15 & 5 & 10 \\
\hline
\end{tabular}

Table 7. Material and state equation parameters of rock

\begin{tabular}{|c|c|c|c|c|c|}
\hline $\begin{array}{c}\text { Mass density, } \\
\mathrm{kg} \cdot \mathrm{m}^{-3}\end{array}$ & $\begin{array}{c}\text { Young's } \\
\text { modulus, } \\
\mathrm{GPa}\end{array}$ & $\begin{array}{c}\text { Poisson's } \\
\text { ratio }\end{array}$ & $\begin{array}{c}\text { Yield stress, } \\
\mathrm{MPa}\end{array}$ & $\begin{array}{c}\text { Tangent } \\
\text { modulus, } \\
\mathrm{GPa}\end{array}$ & $\begin{array}{c}\text { Hardening } \\
\text { parameter }\end{array}$ \\
\hline 2192 & 25.5 & 0.23 & 50.0 & 2.0 & 1.0 \\
\hline
\end{tabular}

Table 8. Material and state equation parameters of explosive (Yang 1996; Preece et al. 1996)

\begin{tabular}{|c|c|c|c|c|c|c|c|c|c|}
\hline $\begin{array}{c}\text { Mass density, } \\
\mathrm{kg} \cdot \mathrm{m}^{-3}\end{array}$ & $\begin{array}{c}\text { Detonation } \\
\text { velocity, } \\
\mathrm{m} \cdot \mathrm{s}^{-1}\end{array}$ & $\begin{array}{c}\text { Detonation } \\
\text { pressure, } \\
\mathrm{GPa}\end{array}$ & $\begin{array}{c}A, \\
\mathrm{GPa}\end{array}$ & $\begin{array}{c}B, \\
\mathrm{GPa}\end{array}$ & $R_{1}$ & $R_{2}$ & $\omega$ & $\begin{array}{c}E_{0}, \\
\mathrm{GPa}\end{array}$ & $V_{0}$ \\
\hline 1100 & 6721 & 3.55 & 5.409 & 0.093 & 4.5 & 1.1 & 0.35 & 0.080 & 1.0 \\
\hline
\end{tabular}

Note: $A, B, R_{1}, R_{2}$ and $\omega$ are all material parameters, where $R_{1}$ and $R_{2}$ are dimensionless parameters and $\omega$ is Grimson constant, indicating the rate of change of pressure relative to internal energy under constant volume condition; $E_{0}$ is the initial internal energy per unit volume; $V_{0}$ is the relative volume. Same as below. 
D.Q. YANG et al.

Table 9. Material and state equation parameters of air

\begin{tabular}{|c|c|c|c|c|c|c|c|c|c|}
\hline $\begin{array}{c}\text { Mass density, } \\
\mathrm{kg} \cdot \mathrm{m}^{-3}\end{array}$ & $C_{0}$ & $C_{1}$ & $C_{2}$ & $C_{3}$ & $C_{4}$ & $C_{5}$ & $C_{6}$ & $\begin{array}{c}E_{0}, \\
\mathrm{GPa}\end{array}$ & $V_{0}$ \\
\hline $1.29 \times 10^{-2}$ & 0 & 0 & 0 & 0 & 0.4 & 0.4 & 0 & 0 & 1.0 \\
\hline
\end{tabular}

Note: $C_{0}-C_{6}$ is the polynomial coefficient of the equation of state of air material.

Table 10. Parameters of the stemming material properties

\begin{tabular}{|c|c|c|c|c|c|c|c|c|}
\hline $\begin{array}{c}\text { Mass } \\
\text { density, } \\
\mathrm{kg} \cdot \mathrm{m}^{-3}\end{array}$ & $\begin{array}{c}\text { Tangent } \\
\text { modulus, } \\
\mathrm{GPa}\end{array}$ & $\begin{array}{c}\text { Volume } \\
\text { modulus, } \\
\mathrm{GPa}\end{array}$ & $A_{0}$ & $A_{1}$ & $A_{2}$ & $P_{c}$ & $E P S_{1}$ & $E P S_{2}$ \\
\hline 1800 & $1.60 \times 10^{-2}$ & 1.328 & 0.0033 & $1.31 \times 10^{-7}$ & 0.1232 & 0 & 0 & 0.05 \\
\hline$E P S_{3}$ & $E P S_{4}$ & $E P S_{5}$ & $E P S_{6}$ & $E P S_{7}$ & $E P S_{8}$ & $E P S_{9}$ & $E P S_{10}$ & $\begin{array}{c}P_{1}, \\
\mathrm{GPa}\end{array}$ \\
\hline 0.09 & 0.11 & 0.15 & 0.19 & 0.21 & 0.221 & 0.25 & 0.30 & 0 \\
\hline$P_{2}$, & $P_{3}$, & $P_{4}$, & $P_{5}$, & $P_{6}$, & $P_{7}$, & $P_{8}$, & $P_{9}$, & $P_{10}$ \\
$\mathrm{GPa}$ & $\mathrm{GPa}$ & $\mathrm{GPa}$ & $\mathrm{GPa}$ & $\mathrm{GPa}$ & $\mathrm{GPa}$ & $\mathrm{GPa}$ & $\mathrm{GPa}$ & $\mathrm{GPa}$ \\
\hline 3.42 & 4.53 & 6.76 & 12.70 & 20.80 & 27.10 & 39.20 & 56.60 & 123.0 \\
\hline
\end{tabular}

Note: $A_{0}, A_{1}, A_{2}$ are yield function constants; $P_{c}$ is the tensile failure truncation pressure; $E P S_{1}-E S_{10}$ are characteristic volumetric strain; $\mathrm{P}_{1}-\mathrm{P}_{10}$ is the pressure corresponding to the characteristic volume strain.

\subsection{SIMULATION RESULTS AND ANALYSIS}

\subsubsection{HOLE PRESSURE ANALYSIS OF SINGLE HOLE DECOUPLED CHARGE WITH DIFFERENT APERTURES}

Three parameters of single-hole blasting with different apertures are set with singlehole numerical simulation to study the shock wave pressure changes under different operating conditions, as shown in Table 11 for different operating parameters.

Table 11. Single hole decoupled charge under different working conditions

\begin{tabular}{|c|c|c|c|c|}
\hline No. & $\begin{array}{c}\text { Charge } \\
\text { structure }\end{array}$ & $\begin{array}{c}\text { Hole diameter, } \\
\mathrm{cm}\end{array}$ & $\begin{array}{c}\text { Charge diameter, } \\
\mathrm{cm}\end{array}$ & $\begin{array}{c}\text { Decoupling } \\
\text { coefficient } / \mathrm{K}_{\mathrm{d}}\end{array}$ \\
\hline 1 & Continuous charge & 1.2 & 0.8 & 1.50 \\
\hline 2 & Continuous charge & 1.8 & 0.8 & 2.25 \\
\hline 3 & Continuous charge & 2.2 & 0.8 & 2.75 \\
\hline
\end{tabular}

Four groups of units were selected on the same horizontal plane of the model, which were $5,10,15$, and $20 \mathrm{~cm}$ away from the center axis of the blast hole respectively. The pressure around the blast hole was observed under different apertures. The 
element selection of each model and the calculation results under the three parameters are shown in Table 12.

Table 12. Selection of different units and pressure peak of single hole decoupling charge

\begin{tabular}{|c|c|c|c|c|c|c|c|c|c|c|c|c|}
\hline$K_{d}$ & \multicolumn{4}{|c|}{1.50} & \multicolumn{5}{c|}{2.25} & \multicolumn{4}{|c|}{2.75} \\
\hline $\begin{array}{c}\bar{r}, \\
\mathrm{~cm}\end{array}$ & 5 & 10 & 15 & 20 & 5 & 10 & 15 & 20 & 5 & 10 & 15 & 20 \\
\hline $\begin{array}{c}\sigma_{r}, \\
\mathrm{MPa}\end{array}$ & 255.3 & 88.9 & 46.7 & 26.8 & 38.2 & 11.1 & 6.5 & 4.2 & 10.3 & 3.6 & 1.6 & 0.8 \\
\hline
\end{tabular}

As can be seen from Table 12, when the hole diameter is $1.2 \mathrm{~cm}$ and the decoupling coefficient is 1.50 , the pressure peak value near the hole wall is $255.3 \mathrm{MPa}$, and the strength of rock with ultimate compressive strength of $80 \mathrm{MPa}$ or above can better protect the hole wall. When the hole diameter is $1.8 \mathrm{~cm}$ and the decoupling coefficient is 2.25 , the pressure peak value near the hole wall is $38.2 \mathrm{MPa}$. For the rock, the pressure peak value is $30-50 \mathrm{MPa}$, and the hole wall can be well protected. When the hole diameter is $2.2 \mathrm{~cm}$ and the decoupling coefficient is 2.75 , the peak pressure near the hole wall is $10.3 \mathrm{MPa}$, which can protect the hole wall well when the rock strength is soft.

\subsubsection{SEAM FORMATION ANALYSIS OF DOUBLE-HOLE DECOUPLED CHARGE BLASTING WITH DIFFERENT APERTURES}

The crack formation process of blasting is the interaction of blasting gas and stress wave. The initial crack is formed in the blast hole wall at first, and then the pre-crack is formed along the line connecting the two holes under the action of stress. In order to study the seam forming process of two-hole decoupling charge with different apertures, a three-dimensional double-hole model is established (Fig. 8). Three groups of simulation models with different blast hole diameters are established respectively for comparative study.

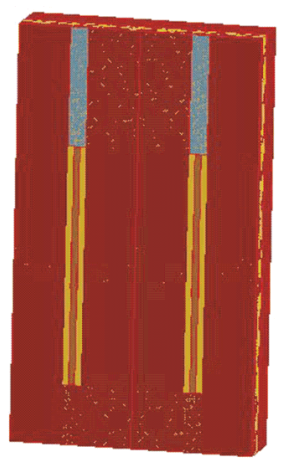

Fig. 8. Schematic diagram of two-hole decoupled charge model 
The failure parameters of the rock material are set by post-processing *MAT_ADD_EROSION, and the element is deleted when the set value of the failure parameters is reached. According to the range of rock tensile stress provided by relevant engineering data, the rock tensile strength of the slope is $26 \mathrm{MPa}$, and the calculated results are shown in Figs. 9-11. The red part is the rock unit and the yellow part is the air, which shows the propagation process of the pre-cracks through the expansion of the air range.

(1) Blasting effect with hole diameter of $1.2 \mathrm{~cm}$

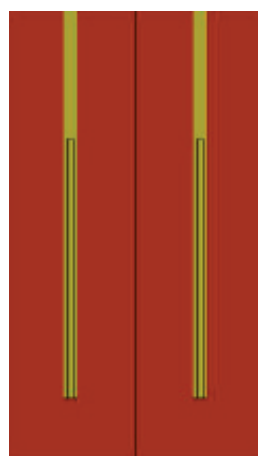

$t=0 \mathrm{~ms}$

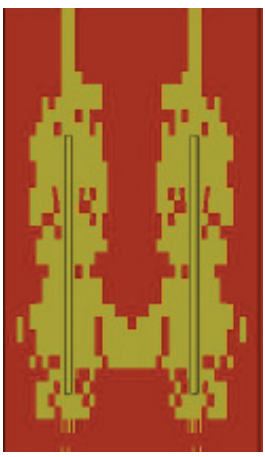

$t=5 \mathrm{~ms}$

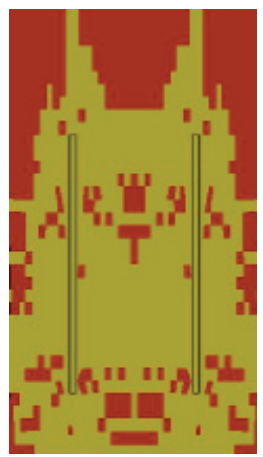

$t=10 \mathrm{~ms}$

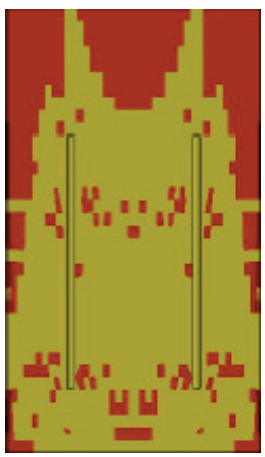

$t=10 \mathrm{~ms}$

Fig. 9. Blasting crack formation

with double-hole decoupling charge hole diameter of $1.2 \mathrm{~cm}$

(2) Blasting effect with hole diameter of $1.8 \mathrm{~cm}$

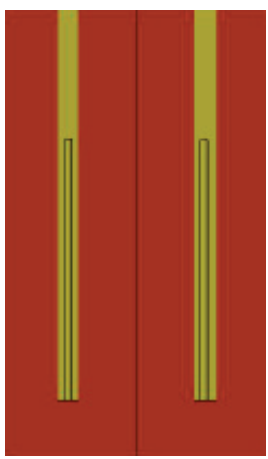

$t=0 \mathrm{~ms}$

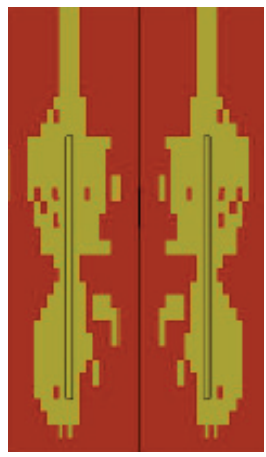

$t=5 \mathrm{~ms}$

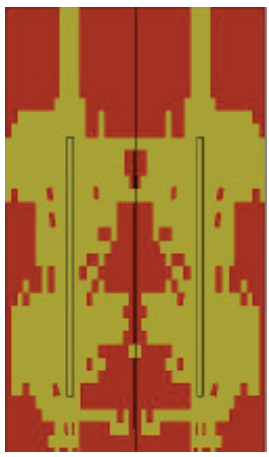

$t=10 \mathrm{~ms}$

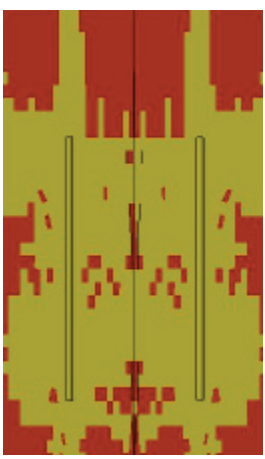

$t=10 \mathrm{~ms}$

Fig. 10. Blasting crack formation

with double-hole decoupling charge hole diameter of $1.8 \mathrm{~cm}$ 
(3) Blasting effect with hole diameter of $2.2 \mathrm{~cm}$

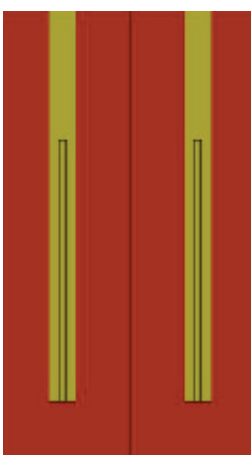

$t=0 \mathrm{~ms}$

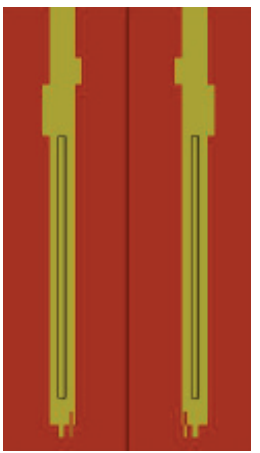

$t=5 \mathrm{~ms}$

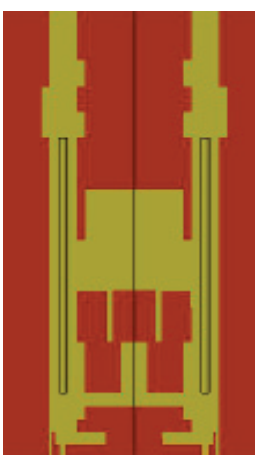

$t=10 \mathrm{~ms}$

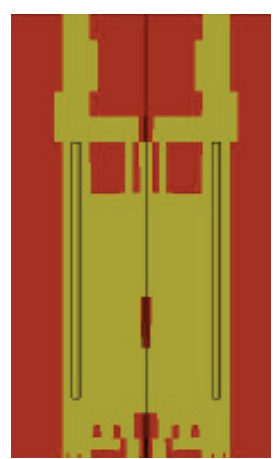

$t=10 \mathrm{~ms}$

Fig. 11. Blasting crack formation

with double-hole decoupling charge hole diameter of $2.2 \mathrm{~cm}$

As shown in Figs. 9-11, after the explosive is detonated, the line connecting the adjacent blast holes can be completely penetrated under the condition of three different apertures, and the effect of seam formation is affected with the increase of the aperture. At the same time, the larger the aperture is, the larger the total failure surface along the seam formation surface is. For the model with $1.2 \mathrm{~cm}$ hole diameter, the adjacent blast holes are basically connected within the whole model range, and for the model with $1.8 \mathrm{~cm}$ hole diameter, the penetration degree of the adjacent blast holes decreases, while for the model with $2.2 \mathrm{~cm}$ hole diameter, the penetration is realized only in the connection direction of the blast holes, and the other side is basically undamaged, so a relatively complete blasting cracks surface can be formed along the connection line of the blast holes. Compared with the three models, the effect of crack formation under $2.2 \mathrm{~cm}$ hole diameter shows the influence of blasting mechanism, that is, the blasting effect is the best when the decoupling coefficient is 2.75 , which is consistent with the conclusion of pressure analysis of single hole decoupling charge with different hole diameter in the previous section.

\subsubsection{ANALYSIS OF BLASTING EFFECT WITH DIFFERENT HOLE SPACING}

As mentioned above, the best blasting effect is obtained when the hole spacing is constant, the hole diameter is $2.2 \mathrm{~cm}$ and the decoupling coefficient is 2.75 . This section analyzes the fragmentation effect of blasting with different hole spacing under the optimal decoupling coefficient of blasting. The different operating parameters are shown in Table 13 and the calculated results of blasting effect with different hole spacing are shown in Figs. 12-14. 
Table 13. Different hole spacing under different working conditions

\begin{tabular}{|c|c|c|c|c|c|}
\hline No. & $\begin{array}{c}\text { Charge } \\
\text { structure }\end{array}$ & $\begin{array}{c}\text { Hole } \\
\text { diameter, cm }\end{array}$ & $\begin{array}{c}\text { Charge } \\
\text { diameter, cm }\end{array}$ & $\begin{array}{c}\text { Decoupling } \\
\text { coefficient, } K_{d}\end{array}$ & $\begin{array}{c}\text { Hole } \\
\text { spacing, cm }\end{array}$ \\
\hline 1 & Continuous charge & 2.2 & 0.8 & 2.75 & 10 \\
\hline 2 & Continuous charge & 2.2 & 0.8 & 2.75 & 15 \\
\hline 3 & Continuous charge & 2.2 & 0.8 & 2.75 & 20 \\
\hline
\end{tabular}

(1) Blasting effect with $10 \mathrm{~cm}$ hole spacing

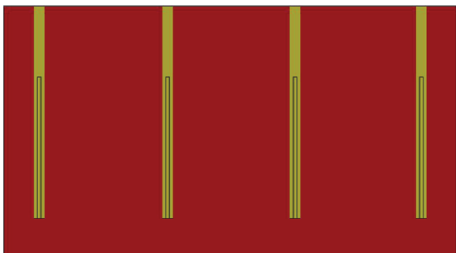

$t=0 \mathrm{~ms}$

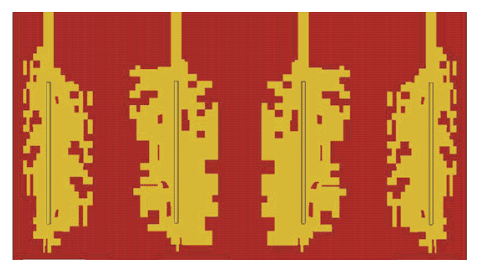

$t=15 \mathrm{~ms}$

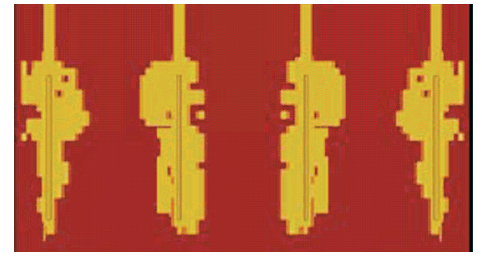

$t=5 \mathrm{~ms}$

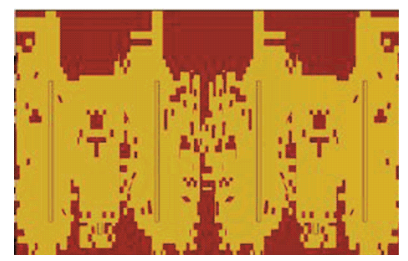

$$
t=20 \mathrm{~ms}
$$

Fig. 12. Blasting effect with $10 \mathrm{~cm}$ hole spacing

(2) Blasting effect of $15 \mathrm{~cm}$ hole spacing

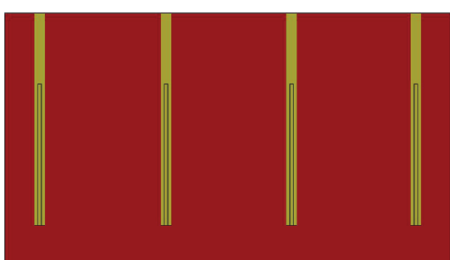

$t=0 \mathrm{~ms}$

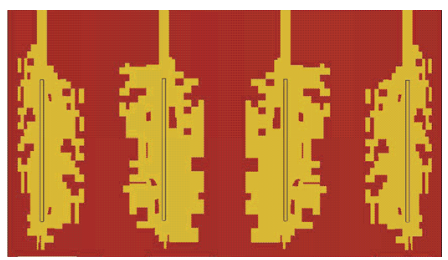

$t=15 \mathrm{~ms}$

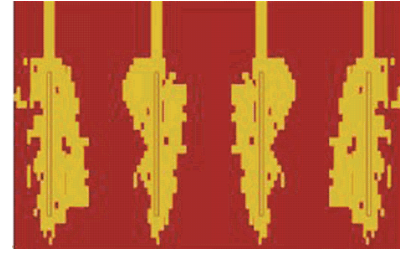

$t=5 \mathrm{~ms}$

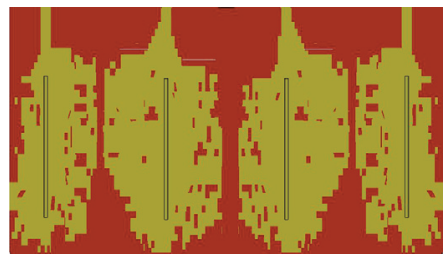

$$
t=20 \mathrm{~ms}
$$

Fig. 13. Blasting effect of $15 \mathrm{~cm}$ hole spacing 
(3) Blasting effect of $20 \mathrm{~cm}$ hole spacing

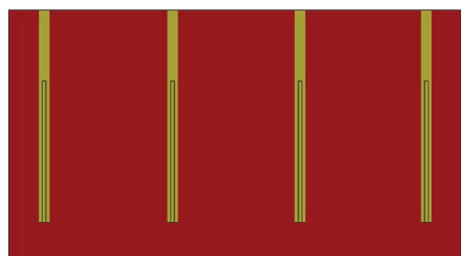

$t=0 \mathrm{~ms}$

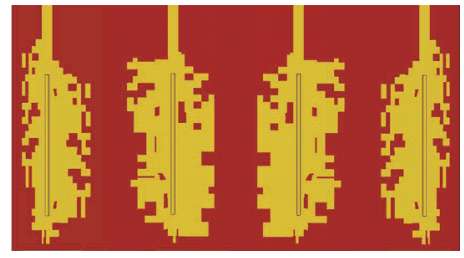

$t=15 \mathrm{~ms}$

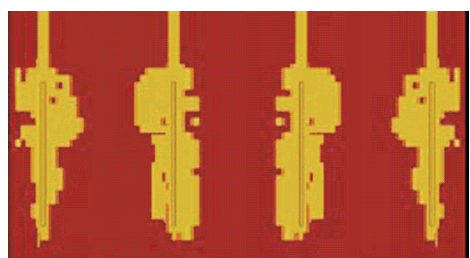

$t=5 \mathrm{~ms}$

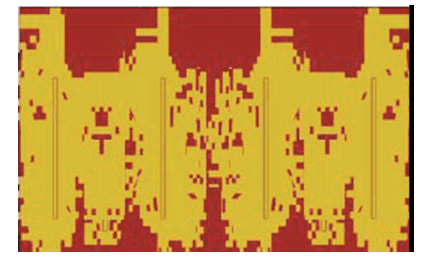

$t=20 \mathrm{~ms}$

Fig. 14. Blasting effect of $20 \mathrm{~cm}$ hole spacing

Compared with the above three kinds of blasting with different hole spacing, the initial crack can be formed at the initial stage of blasting, the difference is small, and the crack propagation speed of blasthole is fast. At that interval of $20 \mathrm{~cm}$ hole at $20 \mathrm{~ms}$, the blasting cracks are partially penetrated; At the distance of $15 \mathrm{~cm}$, the blasting cracks basically penetrate into each other. However, when the hole spacing is $10 \mathrm{~cm}$, the blasting can make most of the connecting lines between adjacent blast holes penetrate, and the blasting effect is better, which shows that the larger the hole spacing is, the less obvious the blasting cracks are.

\section{FIELD TESTS}

A municipal road project includes the civil engineering reservation of rail transit station and related projects. The excavation length of the foundation pit is $240 \mathrm{~m}$, the width is $287.4 \mathrm{~m}$, the relative elevation of the field level is $\pm 0.000 \mathrm{~m}$, the absolute elevation is $1251.79 \mathrm{~m}$, the elevation of the bottom of the pit is $-11.40 \mathrm{~m}$, the absolute elevation is $1240.39 \mathrm{~m}$, the elevation of the municipal connection project is $-18.58 \mathrm{~m}$, the absolute elevation is $1233.21 \mathrm{~m} .300 \mathrm{~m}$ to the east of the explosion area is a brickand-wood structure tile house, lime triad masonry wall wooden structure tile house, the first and second floors of cast-in-place slab roofing houses with brick-and-concrete structure have trees, seedlings and crops on the south, a rural road nearby, the closest distance from a high-speed railway station on the west to a first-class important facility is $125 \mathrm{~m}$, and a project department on the north. The blasting environment is rela- 
tively good, but the practical blasting construction scheme still needs to be selected to ensure the safety of the surrounding environment. In the track area near the west side, the excavation of the high-speed railway slope needs slope control, to maintain the integrity and stability of the slope as far as possible, and at the same time reduce the impact of blasting vibration. Therefore, the blasting of air radial decoupling charge is adopted in slope excavation.

Considering the limitation of test conditions, the manpower and financial resources should be reduced as much as possible without affecting the test results. Combined with the site conditions, four meters of the drilling depth and one meter of the plugging length of the blasting test are set. Six holes are drilled every test. The blasting materials shall be emulsion explosives, ordinary detonating cord, plastic non-electric delay detonating tube detonator, etc. The setting of blasting parameters for the project test is shown in Table 13.

In order to keep the integrity and stability of the slope as much as possible and reduce the influence of blasting vibration, six groups of blasting tests with different hole spacing are carried out according to the actual construction conditions of a municipal road project. The blasting parameters are shown in Table 14. The typical blasting effect is shown in Figs. 15 and 16. The radial decoupling coefficient is 2.75 and the hole spacing is $1.0 \mathrm{~m}$, the blasting effect of the slope is better and the expected purpose is achieved.

Table 14. Setting values of blasting parameters

\begin{tabular}{|c|c|c|c|c|}
\hline $\begin{array}{c}\text { Aperture, } \\
d / \mathrm{mm}\end{array}$ & $\begin{array}{c}\text { Hole deep, } \\
\mathrm{m}\end{array}$ & $\begin{array}{c}\text { Hole spacing, } \\
\mathrm{m}\end{array}$ & $\begin{array}{c}\text { Decoupling } \\
\text { coefficient, } \\
K_{d}\end{array}$ & $\begin{array}{c}\text { Linear } \\
\text { charge density, } \\
\mathrm{g} \cdot \mathrm{m}^{-1}\end{array}$ \\
\hline 140 & 4 & $1.0-1.5$ & $2.0-5.0$ & $500-600$ \\
\hline
\end{tabular}

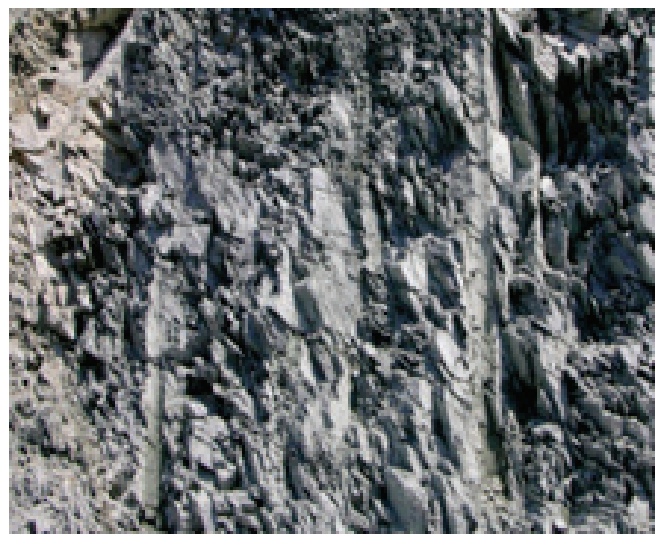

Fig. 15. Effect of $1.0 \mathrm{~m}$ hole spacing blasting test 


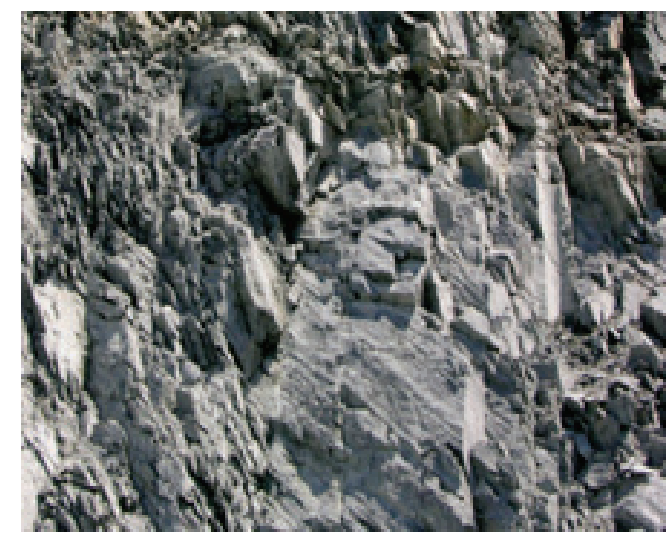

Fig. 16. Effect of $1.2 \mathrm{~m}$ hole spacing blasting test

\section{CONCLUSIONS}

1. Theoretically, it is deduced that the peak pressure of stress wave attenuates rapidly with the increase of proportional distance, and the greater the radial decoupling coefficient of blasting, the slower the peak pressure of stress wave attenuates.

2. The results of stress test show that with the increase of radial decoupling coefficient of blasting, the peak pressure of the same side point obviously decreases. As the distance increases, the slower the stress decays.

3. The ANSYS/LS-DYNA numerical simulation software is used to simulate the pressure variation of different elements around a single-aperture decoupled charge bore. The simulation results show that the larger the decoupling coefficient is, the faster the stress peak around the rock decreases, which verifies the correctness of the theoretical calculation and model test conclusions.

4. By setting the failure parameters of rock materials, the blasting effect under different hole spacing is simulated and analyzed. When the radial decoupling coefficient is 2.75 and the hole spacing is $1.0 \mathrm{~m}$, the blasting effect is the best, and the bigger the hole spacing is, the worse the blasting effect is.

5. The blasting effect with different hole spacing is not that the bigger the hole spacing is, the better the blasting effect is. On the contrary, the bigger the hole spacing is, the worse the blasting effect is, which verifies the accuracy of numerical simulation.

\section{ACKNOWLEDGEMENTS}

This work was supported by the National Natural Science Foundation of China (grant nos. 50704005 and 51664007). 


\section{REFERENCES}

XU L.S., WANG Z.Z., YANG Z.F. et al., 2011, Intermediate coupling device for inclined hole noncoupling charge, China, 201120078082.3.2011-11-09.

QU Y.D., WU M., KONG X.Q. et al., 2014, Numerical simulation of continuation and interval loading in deep-hole blasting, Blasting, Vol. 31, No. 4, 16-21.

YANG G.L., YANG R.S., JIANG L.L., 2012, Pressure distribution along borehole with axial air-deck charge blasting, Explosion and Shock Waves, Vol. 32, No. 6, 653-657.

LING W.M., 2004, Experimental research on explosion pressure on the wall of a borehole in rock, Mining and Metallurgy, Vol. 13, No. 4, 13-16.

YANG X.L., ZHU Y., 1996, Lumpiness problem in coal mining, Coal, Vol. 5, No. 1, 33-35.

WAN Y.L., WANG S.R., 2003, Analyse of impact pressure about de-coupling charge, Blasting, Vol. 18, No. 1, 13-15.

NI Z.F., LI Y.M., 1996, Theoretical calculation and regression on initial shock wave pressure of borehole in rock blasting, Journal of Rock Mechanics and Engineering, Vol. 15, No. S1, 511-514.

LING W.M., 2004, Experimental research on explosion pressure on the wall of a borehole in rock, Mining and Metallurgy, Vol. 13, No. 4, 13-16.

XU Y., ZONG Q., 2001, Theory and application of blasting in underground engineering, University of Mining and Technology Press, Xuzhou, China.

WANG X.G., 2010, Development of a new coal permitted detonating cord, Anhui University of Science and Technology, Huainan.

WANG W. L., 1980, Drilling and blasting, China Coal Industry Publishing House, Beijing, China.

NIU Q., 1990, Mechanism of rock blasting, Northeast Institute of Technology Press, Shenyang.

HAN B., 2013, Model experimental study and application of deep-hole blasting in hard rock for mine shaft, Anhui University of Science and Technology, Huainan.

MA J.J., XIONG Z.Z., DUAN W.D. et al., 2001, Theoretical testing study factors affecting parallel hole cut blasting, Journal of University of Science and Technology (Natural Science Edition), Vol. 24, No. 2, 170-174.

ZONG Q., 2004, Tunneling blasting parameters model experiment study on vertical well freezing soil, University of Science and Technology China, Hefei.

YANG J.R., 1996, A new constitutive model for blast damage, Int. J. Rock Mech. Min. Sci. and Geomech. Abstr., Vol. 33, No. 3, 245-254.

PREECE D.S., THOME B.J., 1996, A study of detonation timing and fragmentation using 3-d finite element techniques and a damage constitutive model, Mohanty (Ed.), Rock Fragmentation by Blasting, Rotterdam, Vol. 33, No. 3, 147-156. 